\section{PEMANTAPAN DAN REFRESHING MATERI ELECTRICAL \& ELECTRONIK UNTUK GURU SMK PENERBANGAN DI JAWA TENGAH DAN SEKITARNYA}

\author{
Sihono', Amal Fatkulloh², Riyanto \\ Saputro ${ }^{3}$, Djoko Herwanto ${ }^{4}$, Nawang \\ Kalbuana ${ }^{5}$, Benny Kurnianto ${ }^{6}$
1,2,3,4,5,6) Politeknik Penerbangan Indonesia Curug

*Nawang Kalbuana

Email :

nawang.kalbuana@ppicurug.ac.id

\begin{abstract}
Teacher's comprehensive view on the competence of electrical and electronic systems of aircraft, especially in some Indonesian Aviation Vocational Schools is still very minimal, although this material is very important to have as one of the competencies of teachers. Politeknik Penerbangan Indonesia Curug as one of the pillars of The Higher Education in the field of Air Transportation under the Ministry of Transportation considers it necessary to do the stabilization and refreshing for the material, so that later it is expected that with the program of community service, especially the teachers of Vocational Aviation around the city of Surakarta and surrounding areas obtain updates related to teaching materials so as to gain a thorough understanding related to science that is continuously progressing. Community Service is carried out for several days both online and offline while paying attention to health protocols as determined by the Task Force Covid 19, so it is expected to get maximum results for teachers, the implementation of Community Service is useful for teachers smk flight with all limitations because it is done during the Covid 19 pandemic.

Keywords: SMK Aviation; stabilization and refreshing; Health protocols
\end{abstract}

\begin{abstract}
Abstrak
Pandangan yang komprehensif Guru terkait kompetensi sistem kelistrikan dan elektronika pesawat udara khususnya dibeberapa SMK Penerbangan Indonesia masihlah sangat minim dimiliki, padahal materi ini sangatlah penting untuk dimiliki sebagai salah kompetensi guru. Politeknik Penerbangan Indonesia Curug sebagai salah satu pilar Perguruan Tinggi Kedinasan dibidang Transportasi Udara dibawah Kementerian Perhubungan memandang perlu untuk melakukan pemantapan dan refreshing untuk materi tersebut, sehingga nantinya diharapkan dengan adanya program pengabdian kepada masyarakat khususnya para guru SMK Penerbangan disekitar wilayah Kota Surakarta dan sekitarnya memperoleh updateing terkait dengan materi ajar sehingga mendapatkan pemahaman menyeluruh terkait dengan keilmuan yang terus menerus mengalami kemajuan. Pengabdian Masyarakat ini dilakukan selama beberapa hari baik secara daring maupun luring dengan tetap memperhatikan protokol kesehatan sebagaimana yang telah ditetapkan oleh satgas Covid 19, sehingga diharapkan akan memperoleh hasil yang lebih maksimal bagi para Guru, pelaksanaan Pengabdian Kepada Masyarakat ini berguna bagi para guru SMK Penerbangan sengan segala keterbatasan karena dilakukan pada masa pandemik Covid 19.

Kata Kunci: SMK Penerbangan; pemantapan dan refreshing; Protokol kesehatan
\end{abstract}


PEMANTAPAN DAN REFRESHING MATERI (ELEKTRIKAL \& ELEKTRONIKA PESAWAT UDARA) UNTUK

GURU SMK PENERBANGAN DI SURAKARTA DAN SEKITARNYA

Sihono, Amal Fatkulloh, Riyanto Saputro, Djoko Herwanto, Nawang Kalbuana, Benny Kurnianto

Volume 1, No. 1, April 2021 hal. 12-19

DOI Artikel : 10.46306/jub.v1i1.2

\section{PENDAHULUAN}

Presiden Republik Indonesia Joko Widodo menegaskan, fokus dunia pendidikan saat ini adalah untuk memberikan keterampilan kerja bagi generasi muda. Hal ini dalam rangka menyambut bonus demografi dan persaingan antarnegara yang semakin ketat. Pendidikan dan pelatihan vokasi/kejuruan akan semakin diperkuat seiring bergesernya strategi pembangunan dari pembangunan infrastruktur fisik menjadi pembangunan manusia (Kemendikbud), Bojongsari, Depok, Jawa Barat, Selasa (12/2/2019).

Untuk mengembangkan pendidikan kejuruan yang selaras dengan kompetensi kebutuhan pengguna lulusan (link and match), Kemendikbud telah melakukan penyesuaian dan pengembangan kurikulum pendidikan kejuruan. Jika sebelumnya menggunakan pendekatan dari supply-driven, maka saat ini kurikulum telah disesuaikan menjadi demand-driven agar dunia usaha dan dunia industri (DUDI) semakin aktif terlibat dalam proses pendidikan kejuruan di SMK (Anwar \& Wailanduw, 2018; Komariah, Kokom; Sofyan, Herminarto;, 2019; Rafidiyah \& Kailani, 2020; Sulistiobudi, 2019; Yusuf \& Mukhadis, 2018).

Berbagai penelitian terkait dunia penerbangan telah banyak dilakukan (Lamtiar et al., 202I)( Desriyanto, Robiansyah, \& Kalbuana, 2020; Sembiring, Rasyid, 202I; Aisyah \& Kalbuana, n.d.; Aisyah, Kalbuana, \& Akuntansi, n.d.; Anam \& Arnas, 2019; Arnas, 2013; Arnas, Kartika, Endrawijaya, \& ..., 2020; Fajar, Kurniawati, 2019; Hermawan, 2009; Hidayat, 2017; N Kalbuana, Kurnianto, Saputro, \& ..., 2020; N Kalbuana, Utami, \& Pratama, 2020; Nawang Kalbuana et al., 2020; Liswand, Riyanti, \& ..., 2020; Putra \& Suprihartini, 2020; Saputro \& Sujanto, 2020; Wahyudi, 2020 ), (Puspita et al., 2020), kesiapan guru dan ketersediaan bahan ajar menjadi tolok ukur awal keberhasilan proses belajar siswa dan pengajaran. Namun pada kenyataannya yang ada saat ini banyak guru SMK Penerbangan bukan berasal dari lulusan SMK penerbangan ataupun lulusan dari kampus yang menyelenggarakan pendidikan di bidang penerbangan, tidak berpengalaman pada perawatan pesawat atau bahkan tidak berlisensi teknisi penerbangan. Namun upaya sekolahan dan kementerian pendidikan telah memberikan bimbinganbimbingan dengan kursus, kunjungan, seminar dan bahkan kerja lapangan. Program pemerintah tersebut tergambar pada Program Revitalisasi SMK dalam Rangka Peningkatan Kualitas dan Daya Saing Sumber Daya Manusia sebagaimana diatur dalam Instruksi Presiden Nomor 9 Tahun 2016. Salah satu usaha yang telah dilakukan di dalam mengatur kegiatan revitalisasi SMK adalah dengan membuat peta jalan pengembangan SMK baik pada pengembangan dan penyelerasan kurikulum, kerjasama sekolah, peningkatan akses sertifikasi lulusan SMK. Berbagai penelitian terkait dengan hal tersebut telah dilakukan Kondisi tersebut memerlukan keseragaman pendalaman akan bahan ajar (Puspita et al., 2020). Bahan ajar yang dimaksud yakni mata pelajaran yang terkait langsung dengan perawatan pesawat terbang. Salah satu buku ajar konsentrasi avionika yakni Electrical \& Electronik Pesawat Udara (Dalkilic, 2017; Gabriel et al., 2019; Hussain et al., 20I4). Kegiatan pengabdian kepada masyarakat di SMK Penerbangan Surakarta ini dimaksudkan untuk mendalami buku ajar sistem elektronika dan listrik pesawat udara, menggunakannya sebagai salah satu sumber belajar bagi guru dan siswa SMK Penerbangan, serta memanfaatkannya untuk 
PEMANTAPAN DAN REFRESHING MATERI (ELEKTRIKAL \& ELEKTRONIKA PESAWAT UDARA) UNTUK GURU SMK PENERBANGAN DI SURAKARTA DAN SEKITARNYA

Sihono, Amal Fatkulloh, Riyanto Saputro, Djoko Herwanto, Nawang Kalbuana, Benny Kurnianto

Volume 1, No. 1, April 2021 hal. 12-19

DOI Artikel : 10.46306/jub.v1i1.2

membuat materi pengajaran di kelas oleh guru dengan tidak menyimpang dari kaidah-kaidah yang dipersyaratkan oleh AMTO-I47 (Embryany \& Ratmanida, 2020). AMTO kepanjangan dari aircraft maintenance training organization, yakni pembelajaran atau training tentang aircraft maintenance yang fokus menyiapkan tenaga ahli dalam bidang teknik guna mendukung industri perawatan pesawat terbang.

\section{METODE PENGABDIAN}

Kegiatan Pengabdian kepada Masyarakat merupakan salah satu pengenjawantahan dari Tridharma perguruab Tinggi yang dilakukan oleh Dosen PPI Curug. Kegiatan ini dilaksanakan dalam bentuk Pendalaman Materi Ajar Electrical \& Electronik Pesawat Udara yang dilaksanakan secara daring dan luring. Kegiatan Online dilaksanakan pada tanggal 5 November 2020 di sekolah masing-masing dengan terlebih dahulu disiapkan link Zoom oleh dosen PPI Curug dan dikirimkan melalui email bagi para pendaftar. Sedangkan kegiatan offline tetap dilaksanakan di salah satu sekolah kejuruan tepatnya di SMK Bina Dirgantara kota Surakarta, selama 3 hari berturut-turut dengan tetap mengikuti protokol kesehatan dengan menjaga jarak, memakai masker, dan mencuci tangan dengan sabun.

Dengan memperhatian kapasitas ruangan kelas, menjaga efektifitas dan melaksanakan protokol kesehatan, maka jumlah peserta dibatasi maksimal 25 orang, yang diatur kemudian untuk mengakomodir guru-guru SMK Penerbangan di wilayah Jawa Tengah dan sekitarnya. Kegiatan Pengabdian Kepada Masyarakat ini ditanggung oleh DIPA PPI Curug khususnya akomodasi Dosen, sedangkan mitra dalam hal ini SMK Bina Dirgantara menyediakan lokasi beserta fasilitas mencuci tangan sebagaimana diatur oleh protokol kesehatan.

Metode yang digunakan adalah berbentuk penyuluhan/sosialisasi dengan mempertimbangkan latar belakang peserta sosialisasi. Penjelasan diberikan dalam bentuk teks dan gambar serta video sehingga mudah dipahami. Setelah kegiatan sosialisasi berakhir diharapkan guru-guru SMK Penerbangan memiliki pandangan yang komprehensif tentang kompetensi sistem kelistrikan dan elektronika pesawat udara, sebagai pengetahuan dasar untuk pelatihan teknis berikutnya pada masa mendatang. Bahan ajar yang digunakan selama kegiatan Pengabdian Kepada masyarakat adalah sebagai berikut:

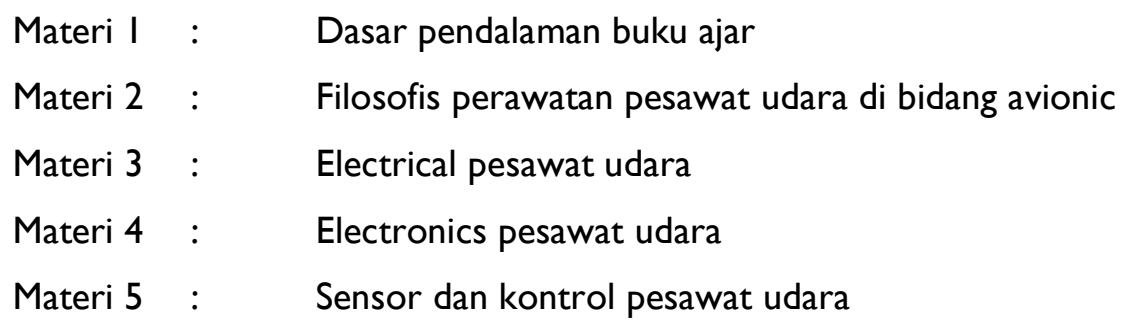

\section{PELAKSANAAN DAN PEMBAHASAN}

Guru-guru SMK Penerbangan pada dasarnya merupakan guru yang tidak memiliki kompetensi pada bidang penerbangan. Dengan mendapatkan pendalaman materi yang sangat mendasar mulai dari filosofis tentang perawatan pesawat udara, sehingga diharapkan dapat memperbaiki kualitas pembelajaran bagi siswa SMK Penerbangan. Dalam kegiatan Pengabdian Kepada Masyarakat ini Guru-guru SMK Penerbangan 
PEMANTAPAN DAN REFRESHING MATERI (ELEKTRIKAL \& ELEKTRONIKA PESAWAT UDARA) UNTUK

GURU SMK PENERBANGAN DI SURAKARTA DAN SEKITARNYA

Sihono, Amal Fatkulloh, Riyanto Saputro, Djoko Herwanto, Nawang Kalbuana, Benny Kurnianto

Volume 1, No. 1, April 2021 hal. 12-19

DOI Artikel : 10.46306/jub.v1i1.2

merupakan peserta mitra Kegiatan Pengabdian Kepada Masyarakat menyediakan sendiri fasilitas yang dibutuhkan selama pelaksanaan workshop pendalaman materi baik yang dilaksanakan secara daring (online/webinar) maupun secara tatap muka (off-line) di SMK Bina Dirgantara Solo. Guru-guru produktif SMK Penerbangan di Semarang, Solo dan Jogjakarta diharapkan membawa materi ajar masing-masing untuk secara bersama-sama diselaraskan dengan acuan AC-I47-02. Sementara SMK Bina Dirgantara sebagai lokai pelaksanaan workshop pendalaman materi secara off-line menyediakan ruangan untuk pelaksanaan pendalaman materi ajar.

\section{Permasalahan yang ditemukan dan solusi yang ditawarkan}

Kesiapan kerja lulusan akan dibuktikan oleh penyerapan lulusan pada industri penerbangan. Maka persoalan yang dihadapi mitra tergambar diantaranya Pemenuhan Guru, Penataan Kelembagaan Refocusing dan Penataan Kompetensi Keahlian. Dari tiga hal tersebut kompetensi menjadi penting dalam filosofi dan implementasi perawatan pesawat terutama bidang avionika (elektronika penerbangan lanjutan). Penataan kompetensi keahlian harus dimulai dari pemahaman guru bidang studi. Kompetensi guru bidang studi dapat tergambar dari latar belakangnya yang bukan lulusan SMK Penerbangan, bukan lulusan dari kampus yang memiliki sertifikasi sebagai lembaga AMTO-I47, serta tidak memiliki latar belakang pernah bekerja sebagai teknisi pemeliharaan pesawat udara. Kondisi ini tentu akan sangat berdampak terhadap bagaimana membawakan materi kompetensi di kelas dan workshop. Pemahaman tentang materi, silabus yang harus disampaikan serta kurikulum yang seharusnya inline dengan kurikulum AMTO-147, memungkinkan untuk disampaikan berbeda bahkan jauh dari yang seharusnya. Kondisi ini tidak jauh berbeda terjadi di SMK Penerbangan lainnya di seluruh wilayah Indonesia.

Guru-guru SMK Penerbangan menyampaikan materi ajar di bidang kelistrikan dan elektronika pesawat udara banyak tidak linear dengan kurikulum dan tujuan pembelajaran pada AMTO-147. PKM ini memberikan peluang untuk guru-guru SMK Penerbangan terutama yang mengajar materi elektrikal dan elektronika pesawat udara untuk mendapatkan bimbingan dan panduan materi ajar, silabus, dan kurikulum yang linear dengan AMTO-I 47.

Hasil dari kegiatan pengabdian kepada masyarakat ini adalah peserta mengikuti kegiatan dengan antusias dan memberikan pertanyaan-pertanyaan mengenai kejadian-kejadian yang pernah terjadi di lingkungan bandar udara sesuai dengan pengalaman mereka.

Berikut dokumentasi kegiatan Pengabdian kepada masyarakat "Pemantapan dan refreshing materi electrical \& electronik untuk guru smk penerbangan di jawa tengah dan sekitarnya” yang dilaksanakan di SMK Bina Dirgantara Surakarta, Jawa Tengah.

a. Rapat persiapan PKM Online dengan Zoom 
PEMANTAPAN DAN REFRESHING MATERI (ELEKTRIKAL \& ELEKTRONIKA PESAWAT UDARA) UNTUK GURU SMK PENERBANGAN DI SURAKARTA DAN SEKITARNYA

Sihono, Amal Fatkulloh, Riyanto Saputro, Djoko Herwanto, Nawang Kalbuana, Benny Kurnianto

Volume 1, No. 1, April 2021 hal. 12-19

DOI Artikel : 10.46306/jub.v1i1.2
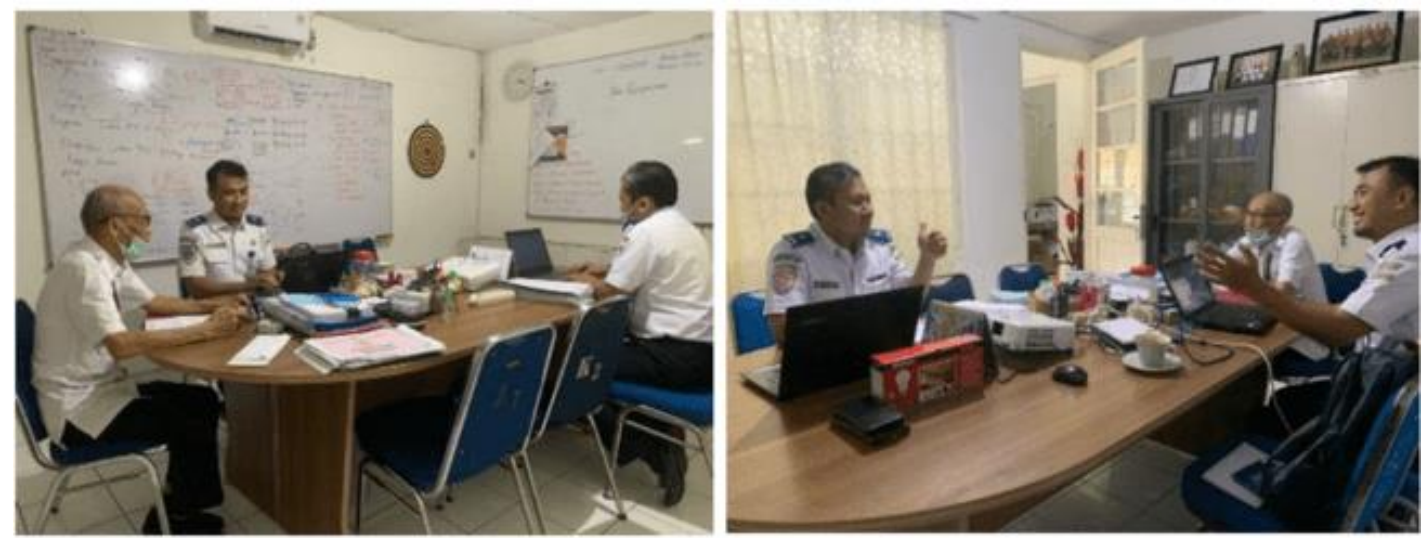

Gambar I. Rapat persiapan PKM Online dengan Zoom

b. Pelaksanaan kegiatan PKM Online
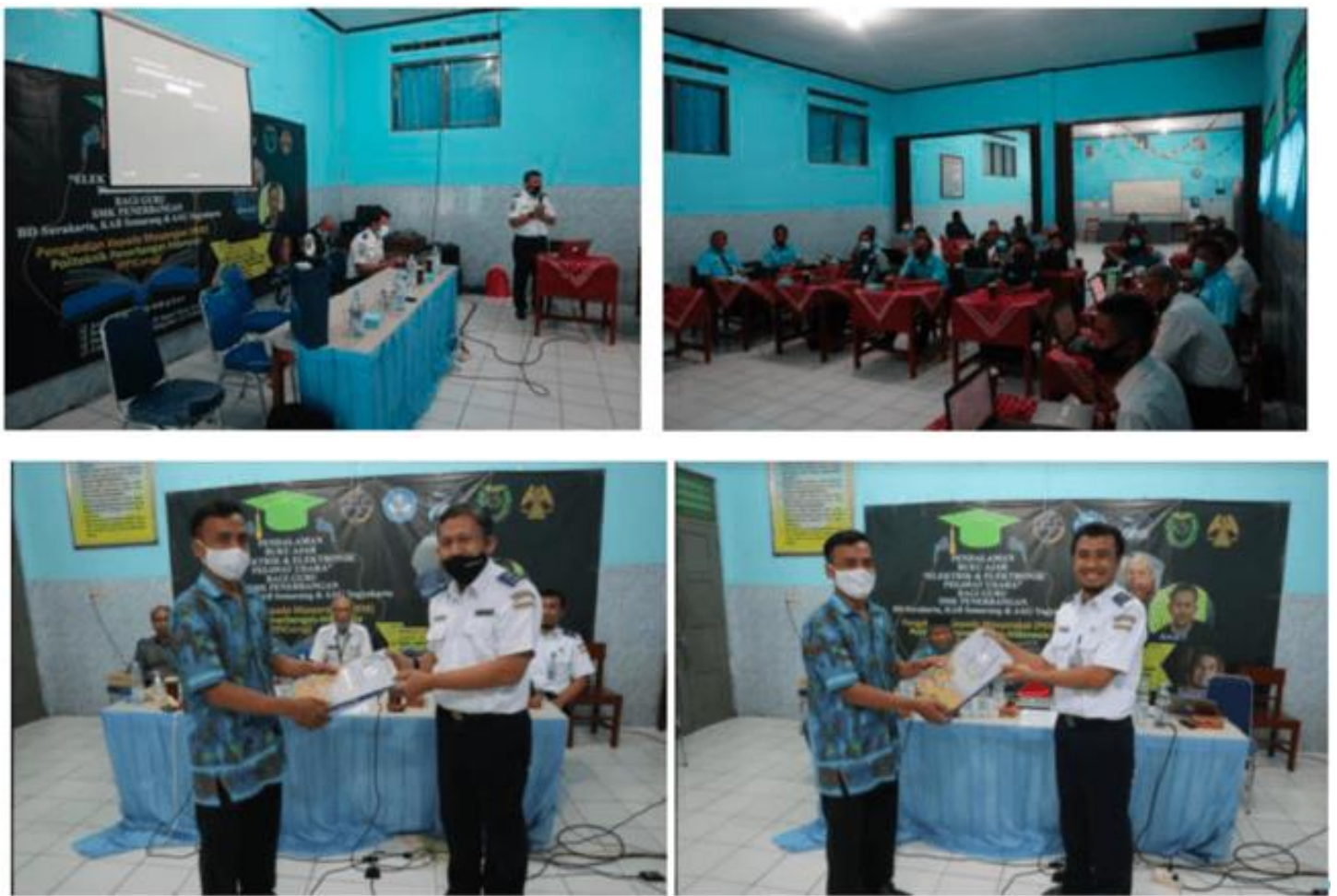

Gambar 2. Pelaksanaan kegiatan

c. Daftar hadir kegiatan Pengabdian Kepada Masyarakat

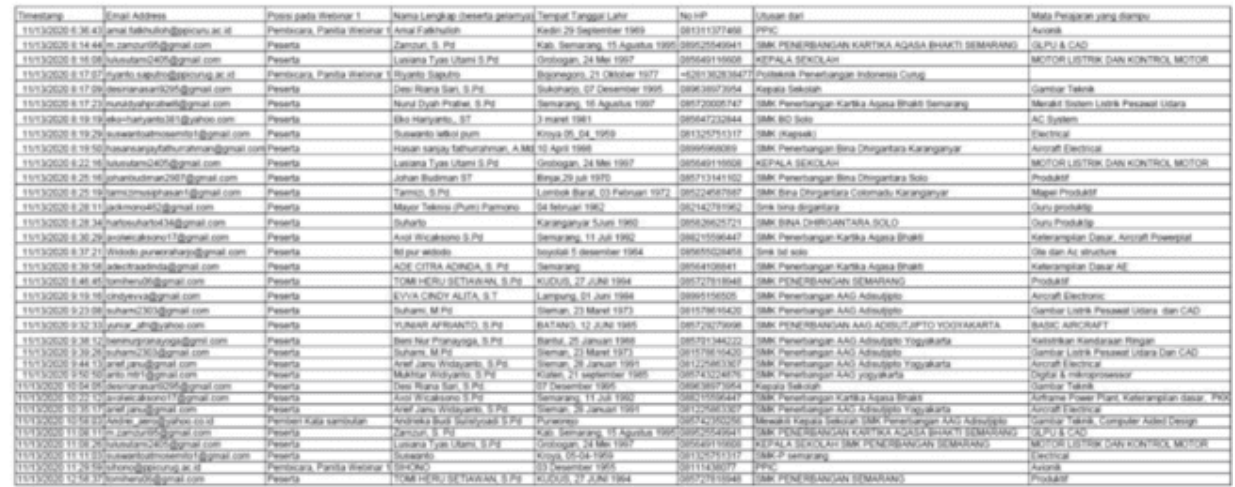


PEMANTAPAN DAN REFRESHING MATERI (ELEKTRIKAL \& ELEKTRONIKA PESAWAT UDARA) UNTUK

GURU SMK PENERBANGAN DI SURAKARTA DAN SEKITARNYA

Sihono, Amal Fatkulloh, Riyanto Saputro, Djoko Herwanto, Nawang Kalbuana, Benny Kurnianto

Volume 1, No. 1, April 2021 hal. 12-19

DOI Artikel : 10.46306/jub.v1i1.2

\section{Gambar 3. Daftar hadir kegiatan Pengabdian Kepada Masyarakat}

\section{KESIMPULAN DAN SARAN}

Pemahaman guru SMK Penerbangan secara umum tentang industri penerbangan masihlah sangat minim, sehingga berdampak pada penyusunan bahan ajar yang disampaiakn kepada siswa yang lebih berdasarkan pada literatur dari internet, kurang didukung dengan literatur dokumen/buku tentang sistem pemeliharaan pesawat udara. Keterbatasan pengetahuan Guru SMK Penerbangan banyak dipengaruhi oleh latar belakang mereka yang tidak pernah berhubungan dengan industri penerbangan baik di industri pesawat udara, bandara, maupun rantai pasokan lainnya di dunia penerbangan. Pelaksanaan kegiatan Pengabdian Kepada Masyarakat dilaksanakan dengan sangat antusias oleh guru-guru disekitar Jawa Tengah, Para Guru memanfaatkannya untuk membuat materi pengajaran di kelas oleh guru dengan tidak menyimpang dari kaidah-kaidah yang dipersyaratkan oleh AMTO-147. Banyak pertanyaan-pertanyaan yang diajukan pada saat kegiatan ini sehingga para guru dapat memperoleh gambaran yang menyeluruh terkait dengan materi ajar ini karena memperoleh jawaban dari para Dosen yang telah memiliki pengalaman dibidang Penerbangan.

Dengan adanya kegiatan ini disarankan dari guru-guru SMK agar Politeknik Penerbangan Indonesia Curug dapat semakin meningkatkan kepeduliannya dalam memberikan pelatihan-pelatihan dasar penerbangan kepada Guru-Guru SMK Penerbangan Indonesia agar materi ajar sesuai dengan perkembangan yang terbaru dan diharapkan dapat menjadikannya sebagai mitra binaan baik dalam skala lokal maupun nasional.

\section{UCAPAN TERIMA KASIH}

Kegiatan Pengabdian Kepada Masyarakat tentang Pemantapan Dan Refreshing Materi Electrical \& Electronik Untuk Guru Smk Penerbangan Di Jawa Tengah Dan Sekitarnya ini didanai dari DIPA Politeknik Penerbangan Indonesia tahun anggaran 2020, kami juga mengucapkan terima kasih kepada para guru SMK Penerbangan yang selalu aktif pada saat kegiatan ini dilaksanakan dan khusunya SMK Bina Dirgantara yang telah menyediakan ruangan sehingga pelaksaaan kegiatan ini dapat dilaksanakan. .

\section{DAFTAR PUSTAKA}

..., Desriyanto, N., Robiansyah, R., \& Kalbuana, N. (2020). Making Modeling Control System Of The Use Of Electrical Energy In A Flight Engineering Department Building Stpi Curug-Tangerang. International Journal of ....

..., Sembiring, D., Rasyid, S., Kalbuana, N., \& ... (202I). Macroeconomic effect on stock price: Evidence from Indonesia. ....

Aisyah, S., \& Kalbuana, N. (n.d.). Sistem Pendukung Keputusan Pemilihan Database Menggunakan Metode Analytical Hierarchy Process (AHP). CSRID Journal.

Aisyah, S., Kalbuana, P. N., \& Akuntansi, J. K. (n.d.). SIMULASI TEKNOLOGI MOBILE DENGAN APLIKASI JAVA 2 MICRO EDITION PADA SISTEM INFORMASI AKADEMIK.

Anam, K., \& Arnas, Y. (2019). METODA CRAMER UNTUK SOLUSI ANALISA RANGKAIAN LISTRIK 
PEMANTAPAN DAN REFRESHING MATERI (ELEKTRIKAL \& ELEKTRONIKA PESAWAT UDARA) UNTUK

GURU SMK PENERBANGAN DI SURAKARTA DAN SEKITARNYA

Sihono, Amal Fatkulloh, Riyanto Saputro, Djoko Herwanto, Nawang Kalbuana, Benny Kurnianto

Volume 1, No. 1, April 2021 hal. 12-19

DOI Artikel : 10.46306/jub.v1i1.2

MENGGUNAKAN SCILAB. Langit Biru: Jurnal IImiah Aviasi.

Anwar, N., \& Wailanduw, A. G. (2018). Evaluasi Pelaksanaan dan Faktor-Faktor Penghambat dan Pendukung Teaching Factory di SMK Negeri 3 Surabaya. Jurnal Pendidikan Teknik Mesin.

Arnas, Y. (2013). Analisis Kebutuhan Daya Listrik di Bandar Udara Cakrabhuwana Cirebon. Jurnal Aviasi Langit Biru.

Arnas, Y., Kartika, B., Endrawijaya, I., \& ... (2020). Teknik Pengelasan Listrik Diklat Pemberdayaan Masyarakat. ... (JPKM) Langit Biru.

Dalkilic, S. (2017). Improving aircraft safety and reliability by aircraft maintenance technician training. Engineering Failure Analysis. https://doi.org/10.1016/j.engfailanal.2017.06.008

Embryany, F., \& Ratmanida. (2020). A Need Analysis of English Learning for the Aircraft Maintenance Students. https://doi.org/|0.299|/assehr.k.200217.008

Fajar, M., Kurniawati, Z., \& ... (2019). RANCANGAN SIMULASI APPRAOCH LIGHTING SYSTEM BANDAR UDARA MENGGUNAKAN MICROSOFT VISUAL STUDIO 2015 DI SEKOLAH TINGGI .... Langit Biru: Jurnal Ilmiah ....

Gabriel, O. E., Esther, A. U., Kole, U. O., \& Adekunle, S. M. (2019). Development of an error detection instrument for aircraft maintenance. International Journal of Engineering Research in Africa. https://doi.org// 0.4028/www.scientific.net/JERA.45.156

Hermawan, I. (2009). KONSEP SISTEM MANAJEMEN PERAAWATAN PERALATAN ELEKTRONIKA DAN LISTRIK BANDARA. Langit Biru: Jurnal IImiah Aviasi.

Hidayat, Z. (20I7). PERANCANGAN TURBIN AKSIAL SATU TINGKAT UNTUK MESIN TURBOJET BERBASIS TURBOCHARGER T70. Langit Biru: Jurnal Ilmiah Aviasi.

Hussain, W., Zahra, J., Anwar, S., \& Abdul Aziz, D. S. (20I4). Implementation of Total Quality Management at Aircraft Maintenance Department. IOSR Journal of Humanities and Social Science. https://doi.org//0.9790/0837-1917/01105

Kalbuana, N, Kurnianto, B., Saputro, R., \& ... (2020). The Effect of Audit Quality, Managerial ownership, Institutional ownership, and Intellectual Capital toward Earning Management on Transportation Corporations in .... Solid State ....

Kalbuana, N, Utami, S., \& Pratama, A. (2020). Pengaruh Pengungkapan Corporate Social Responsibility, Persistensi Laba dan Pertumbuhan Laba Terhadap Manajemen Laba Pada Perusaaan Yang Terdaftar di .... Jurnal Ilmiah Ekonomi Islam.

Kalbuana, Nawang, Yulistian, N., Nugroho Budi, A., Penerbangan, P., Curug, I., Teknologi, I., Bisnis, D., \& Dahlan Jakarta, A. (2020). Pengaruh Intellectual Capital, Tata Kelola Perusahaan Dan Kualitas Audit Terhadap Manajemen Laba. Jurnal Akuntansi Berkealnjutan Indonesia, 3(I).

Komariah, Kokom; Sofyan, Herminarto;, W. (2019). PROBLEM-BASED LEARNING: IMPLEMENTASI DAN URGENSINYA BAGI PENINGKATAN KUALITAS PEMBELAJARAN. Jurnal Kependidikan: 
PEMANTAPAN DAN REFRESHING MATERI (ELEKTRIKAL \& ELEKTRONIKA PESAWAT UDARA) UNTUK

GURU SMK PENERBANGAN DI SURAKARTA DAN SEKITARNYA

Sihono, Amal Fatkulloh, Riyanto Saputro, Djoko Herwanto, Nawang Kalbuana, Benny Kurnianto

Volume 1, No. 1, April 2021 hal. 12-19

DOI Artikel : 10.46306/jub.v1i1.2

Penelitian Inovasi Pembelajaran.

Lamtiar, S., Arnas, Y., Rusdiyanto, A. A., \& ... (202I). Liquidity Effect, Profitability Leverage to Company Value: A Case Study Indonesia. European Journal of ....

Liswand, F., Riyanti, L. E., \& ... (2020). PERENCANAAN KEBUTUHAN SUKU CADANG PESAWAT PIPER PA-28-I8I ARCHER III UNTUK MELAKSANAKAN PROGRAM PERAWATAN TAHUN 2020 DI .... Langit Biru: Jurnal ....

Puspita, H., Ana, A., Wulandari, I. Y., \& Andriana. (2020). The evaluation of the learning curriculum of the aircraft maintenance training organization 147 for avionic study program as a basis in meeting the need of the aviation industry. Journal of Engineering Education Transformations. https://doi.org//0.16920/JEET/2020/V34I0/I57848

Putra, I., \& Suprihartini, Y. (2020). SISTEM MONITORING OPERASIONAL LAMPU RUNWAY THRESHOLD IDENTIFICATION LIGHT (RTIL) DI LABORATORIUM AIRFIELD GROUND LIGHTING .... Langit Biru: Jurnal Ilmiah ....

Rafidiyah, D., \& Kailani, A. (2020). Identifikasi Potensi Smk Muhammadiyah Sebagai Lembaga Pendidikan Vokasi Yang Berkemajuan: Studi Fenomenologi Terhadap Penerapan Program Revitalisasi SMK Di Indonesia. Pedagogik: Jurnal Pendidikan. https://doi.org/I0.33084/pedagogik.vI 5il. 1284

Saputro, R., \& Sujanto, S. B. (2020). Cadet Management at Aviation Schools: A Case Study at Politeknik Penerbangan Indonesia Curug. Psychology and ....

Sulistiobudi, R. A. (2019). EFEKTIVITAS CAREER DEVELOPMENT LEARNING PROGRAM UNTUK MEMPERSIAPKAN EMPLOYABILITY DEVELOPMENT PADA SISWA SMK. Journal of Psychological Science and Profession. https://doi.org//0.24198/jpsp.v2i3.19382

Wahyudi, J. (2020). MODIFIKASI MEDIA PEMBELAJARAN PRAKTEK SISTEM KELISTRIKAN PESAWAT UDARA DARI SISTEM ANALOG MENJADI SISTEM DIGITAL, PRODI TEKNIK .... Langit Biru: Jurnal Ilmiah Aviasi.

Yusuf, A. R., \& Mukhadis, A. (20I8). MODEL PENGEMBANGAN PROFESIONALITAS GURU SESUAI TUNTUTAN REVITALISASI PENDIDIKAN VOKASI DI INDONESIA. Lectura: Jurnal Pendidikan. https://doi.org//0.31849/lectura.v9i2.1613 